\title{
Expression and gene polymorphisms of the chemokine CXCL5 in colorectal cancer patients
}

\author{
JAN DIMBERG $^{1}$, OLAF DIENUS ${ }^{2}$, STURE LÖFGREN ${ }^{2}$, ANDERS HUGANDER $^{3}$ and DICK WÅGSÄTER ${ }^{4}$ \\ ${ }^{1}$ Department of Natural Science and Biomedicine, University College of Health Sciences; Departments of ${ }^{2}$ Clinical Microbiology \\ and ${ }^{3}$ Surgery, Ryhov County Hospital, Jönköping; ${ }^{4}$ Atherosclerosis Research Unit, King Gustav V \\ Research Institute, Department of Medicine, Karolinska Institute, Stockholm, Sweden
}

Received February 15, 2007; Accepted March 30, 2007

\begin{abstract}
Several studies indicate that chemokines play important roles in colorectal mucosal immunity by recruiting leukocytes into and out of the lamina propria adjacent to the epithelium. The chemokine CXCL5 which is expressed by epithelial cells within colorectal mucosa is a chemoattractant for neutrophils and has been implicated in Crohn's disease and ulcerative colitis. In addition, CXCL5 is one chemokine which promote angiogenesis related to cancer. The objective of this study was to determine by ELISA assay whether CXCL5 protein level is altered in colorectal cancer (CRC) tissues $(n=80)$ compared with paired normal mucosa. Furthermore, the plasma CXCL5 levels from CRC patients $(n=62)$ compared with controls $(n=71)$ were also examined. Using a TaqMan system we screened for $-156 \mathrm{G} \rightarrow \mathrm{C}$ and $+398 \mathrm{G} \rightarrow$ A CXCL5 gene variants in CRC patients $(n=228)$ and a control group $(n=231)$ to assess the role of CXCL5 genotype in CRC. The analyses showed that CXCL5 protein level in colorectal tumours was significantly $(\mathrm{P}<0.0001)$ higher than in normal tissue and was lower in plasma in CRC patients compared with controls $(\mathrm{P}=0.026)$. Immunohistochemistry revealed CXCL5 immunoreactivity mainly in epithelial cells of the colorectal carcinoma and in normal epithelial cells. Furthermore, patients who were $-156 \mathrm{C}$ carriers had higher CXCL5 protein concentration compared with $-156 \mathrm{G}$ carriers in normal tissue $(\mathrm{P}=0.027)$ and CXCL5 protein levels in cancerous tissue tended to be higher for the patient $-156 \mathrm{C}$ carriers $(\mathrm{P}=0.059)$. To our knowledge this is the first report on the influence of CXCL5 gene variants and their relation to expression of CXCL5 protein in human CRC.
\end{abstract}

Correspondence to: Dr Jan Dimberg, Department of Natural Science and Biomedicine, University College of Health Sciences, Box 1026, SE-551 11 Jönköping, Sweden

E-mail: jan.dimberg@hhj.hj.se

Key words: CXCL5, polymorphism, tissue level, colorectal cancer, IL-13

\section{Introduction}

Chemokines are chemotactic cytokines that are responsible for the attraction and guidance of leukocytes expressing chemokine receptors and play an important role in local immunoregulation. These phenomena have impact on inflammation and carcinogenesis of which leukocyte infiltration is an important evidence of almost all cancers (1-3).

CXCL5, also referred to as ENA-78, is predominantly an enterocyte-derived, neutrophil-activating chemokine that may play a partial role in neutrophil recruitment from the lamina propria into the epithelial layer in the gastrointestinal tract (4-6). Other cell types, including monocytes and endothelial cells, are producing CXCL5 to some extent $(6,7)$. IL-1ß has been suggested to be one of the regulators of CXCL5 expression in colonic epithelial cells and also found in higher level in colorectal carcinomas compared with normal tissue $(6,8)$.

CXCL5 is related to growth-related oncogene protein (GRO) $\alpha$ (sequence identity 52\%) and IL-8 (sequence identity $22 \%$ ) and acts through the same type of receptors as these chemokines (9). Interestingly, GRO $\alpha$ is more highly expressed in neoplastic than normal colon epithelium (10) and is also, as CXCL5, a potential neutrophile chemoattractant.

CXCL5 belongs to the glutamic acid-leucine-arginine (ELR) motif containing chemokines, which promotes angiogenesis (11), and has been suggested to be one of the chemokines, including IL-8 and GRO $\alpha$, which promote angiogenesis related to cancer (12). Furthermore, CXCL5 has been shown to highly correlate with human non-small cell lung cancer derived angiogenesis (13).

CXCL5 has also been studied in diseases of the intestine where it is expressed by epithelial cells of the intestinal mucosa of patients with Crohn's disease, ulcerative colitis and gastritis $(6,14,15)$. Investigation by Keates et al showed that mRNA and protein of CXCL5 from patient tissues with ulcerative colitis expressed higher levels compared with normal controls (6).

Immunohistochemical studies in normal human colon and in ulcerative colitis demonstrate CXCL5 immunoreactivity principally associated with crypt epithelial cells (6). Two single nucleotide polymorphisms (SNPs) have been reported in the literature of the CXCL5 gene, located in the promoter 
as a $\mathrm{G} \rightarrow \mathrm{C}$ change at position -156 (rs352046) and in exon 2 as a $\mathrm{G} \rightarrow \mathrm{A}$ change at position +398 (rs425535) (16). The polymorphism in the promoter is suggested to occur at a transcription factor binding site for myeloid zinc finger proteins, whereas the polymorphism in exon 2 results in a synonymous substitution, predicted to occur at a splicing enhancer site $(16,17)$. There are limited reports concerning the functional relevance of these polymorphic sites. However, a genotype effect has been demonstrated for the polymorphism in the promoter and CXCL5 concentration in human plasma (18).

Based on the suggested role of CXCL5 in the pathogenesis of certain diseases we performed an examination of the association of the CXCL5 gene variant and CXCL5 protein expression in colorectal cancer (CRC) patients.

\section{Materials and methods}

Patients and controls for CXCL5 genotyping. This study comprised blood samples, which were obtained from 228 patients from South-eastern Sweden, who underwent surgical resections for primary colorectal adenocarcinomas at the Department of Surgery, Ryhov County Hospital, Jönköping, Sweden. This patient group comprised 116 males and 112 females. The mean age was 70 years (range 29-93) and all tumours were classified according to Dukes' classification system: stage A $(n=41)$, stage $B(n=98)$, stage $C(n=78)$ and stage $D(n=11)$. The tumours were localized in the colon $(\mathrm{n}=118)$ and rectum $(\mathrm{n}=110)$.

Blood-control donors $(\mathrm{n}=231)$, with no known CRC history, were selected from Ryhov County Hospital. The control group consisted of 123 males and 108 females with a mean age of 67 years (range 50-93). All blood-controls were from the same geographical region as the CRC patients and all cases and controls were of Swedish Caucasian origin.

Plasma samples. Sixty-two of the CRC patients and 71 healthy blood donors were available for plasma collection. Blood was collected before surgery and all blood, including controls, were separated by centrifugation within $1 \mathrm{~h}$. Plasma was removed and stored at $-70^{\circ} \mathrm{C}$. The group of $\mathrm{CRC}$ patients comprised of 34 males and 28 females with the mean age of 68 years (range 29-89). The patient tumours were categorized according to Dukes' classification; stage A $(n=14)$, stage B $(n=26)$ and stage $C(n=22)$. Thirty-three tumours were located in the rectum and 29 in the colon. Plasma that was available for controls included 37 males and 34 females with a mean age of 60 years (range 55-67).

Patients and tissue sampling. This study utilized tissue samples which were available from 80 of the CRC patients. The sporadic tumours from 44 males and 36 females with a mean age of 69 years (range 29-90) were collected and classified according to Dukes' classification system: stage A $(n=14)$, stage $B(n=34)$ and stage $C(n=32)$. The tumours were localized in the colon $(n=38)$ and rectum $(n=42)$. From each patient tumour tissue and adjacent normal mucosa (about $5 \mathrm{~cm}$ from the tumour) were excised and immediately frozen at $-70^{\circ} \mathrm{C}$ until analysis.

ELISA. CXCL5 in plasma and tissue was measured using an established commercially available enzyme-linked immuno- sorbent (ELISA) kit (R\&D Systems Europe, UK) following the manufacturer's instructions. Protein expression of IL-1ß was also determined in an available subset including 48 CRC tissue and adjacent normal mucosa (R\&D Systems). The plasma CXCL5 concentration from CRC patients and control subjects was expressed as picograms per millilitre $(\mathrm{pg} / \mathrm{ml})$ and the CXCL5 and IL-1ß protein levels of cancer and paired normal tissues from the CRC patients were expressed as picograms per milligram of protein $(\mathrm{pg} / \mathrm{mg})$.

Tissue protein preparation. Frozen tumour tissue and normal mucosa were thawed, homogenised in ice cold lysis buffer containing PBS (9.1 mM dibasic sodium phosphate, $1.7 \mathrm{mM}$ monobasic sodium phosphate, $150 \mathrm{mM} \mathrm{NaCl}, \mathrm{pH} 7.4$ ) and $1 \%$ Nonidet P-40, $0.5 \%$ sodium deoxycholate, $0.1 \%$ sodium dodecyl sulphate (SDS), $100 \mu \mathrm{g} / \mathrm{ml}$ phenylmethylsulphonyl flouride (PMSF), $2 \mu \mathrm{g} / \mathrm{ml}$ aprotinin, $1 \mathrm{mM}$ sodium orthovanadate and $1 \mu \mathrm{g} / \mathrm{ml}$ leupeptin. The lysate was placed on ice for $30 \mathrm{~min}$ and then centrifuged at $13000 \mathrm{~g}$ for $10 \mathrm{~min}$. Protein content of the supernatant fluid was determined for each sample using the Bradford protein assay (Bio-Rad Laboratories, UK).

Immunohistochemistry. Twelve tumour samples were available for immunohistochemical staining to study the cell type origin of the CXCL5 expression. Staining was performed using a standard protocol on $4-\mu \mathrm{m}$ sections from formalin-fixed paraffin-embedded tissue blocks. Endogenous peroxidase activity was quenched by treatment with $3 \%$ hydrogen peroxide for $5 \mathrm{~min}$. Sections were subsequently incubated with a primary goat anti-human polyclonal CXCL5 antibody (R\&D Systems Europe) in appropriate dilution overnight at $4^{\circ} \mathrm{C}$. After rinsing in Tris-buffered saline, sections were incubated with secondary biotinylated horse anti-goat IgG (Santa Cruz Biotechnology USA). Avidin-biotin peroxidase complexes (Dako Cytomation Denmark) were added followed by visualization with 3,3'-diaminobenzidine tetrahydrochloride (Dako Cytomation). All sections were counterstained with Mayer's hematoxylin (Histolab Products AB, Sweden).

CXCL5 genotype determination. The blood was stored frozen until DNA was extracted using QIAamp DNA blood kit (Qiagen, CA, USA). DNA samples were genotyped using 5'-exonuclease allelic discrimination assay (Applied Biosystems, USA). C__26260418_10 and C___1015616_10 TaqMan SNP genotyping assays were used for analysis of rs352046 and rs425535 genotype respectively (Applied Biosystems). A total of $12.5 \mathrm{ng}$ DNA was amplified in a total volume of $12 \mu \mathrm{l}$ containing $1 \mathrm{X}$ TaqMan Universal PCR master mix (Perkin-Elmer, Applied Biosystems) including $1 \mathrm{X}$ TaqMan SNP genotyping assay. Amplification was performed by an initial cycle of $50^{\circ} \mathrm{C}$ for $2 \mathrm{~min}, 95^{\circ} \mathrm{C}$ for 10 min followed by 40 cycles of $95^{\circ} \mathrm{C}$ for $15 \mathrm{sec}$ and $60^{\circ} \mathrm{C}$ for 1 $\min$. The post-PCR end-point plate was read using the 7500 Fast Real-Time PCR system (Applied Bio-systems). The manual calling option in the allelic discrimination application ABI PRISM 7500 SDS software version 1.3.1 was then used to assign genotypes.

Statistical analysis. Differences in the frequencies of the CXCL5 polymorphisms between CRC patients and the control 
Table I. Genotypic and allelic distributions in \% (n) of the promoter and exon 2 CXCL5 gene polymorphisms in CRC patients and controls.

\begin{tabular}{|c|c|c|c|c|c|}
\hline Genotype & $\mathrm{CRC}(\mathrm{n}=228)$ & Controls $(n=231)$ & Allele & CRC ( $n=456$ alleles $)$ & Controls ( $n=462$ alleles) \\
\hline \multicolumn{6}{|l|}{ Promoter } \\
\hline \multicolumn{6}{|l|}{$-156 \mathrm{G} \rightarrow \mathrm{C}$} \\
\hline $\mathrm{G} / \mathrm{G}$ & $74.1(169)$ & $78.4(181)$ & $\mathrm{G}$ & $86.2(393)$ & $88.7(410)$ \\
\hline $\mathrm{G} / \mathrm{C}$ & $24.1 \quad(55)$ & $20.8 \quad(48)$ & & & \\
\hline $\mathrm{C} / \mathrm{C}$ & $1.8 \quad$ (4) & $0.8 \quad$ (2) & $\mathrm{C}$ & $13.8 \quad(63)$ & $11.3 \quad(52)$ \\
\hline \multicolumn{6}{|l|}{$\begin{array}{l}\text { Exon } 2 \\
+398 \mathrm{G} \rightarrow \mathrm{A}\end{array}$} \\
\hline $\mathrm{G} / \mathrm{G}$ & $75.0(171)$ & 78.8 (182) & G & $86.6(395)$ & $89.0(411)$ \\
\hline G/A & $23.2 \quad(53)$ & $20.4 \quad(47)$ & A & $13.4(61)$ & $11.0 \quad(51)$ \\
\hline $\mathrm{A} / \mathrm{A}$ & $1.8 \quad(4)$ & $0.8 \quad(2)$ & & & \\
\hline
\end{tabular}

CRC patients vs controls: promoter genotypes overall $\mathrm{P}=0.464$, promoter alleles $\mathrm{P}=0.241$, exon 2 genotypes overall $\mathrm{P}=0.509$, exon 2 alleles $\mathrm{P}=0.279$.

group and between clinical data within the CRC subgroup were analyzed using the $\chi^{2}$ test and the Hardy-Weinberg equilibrium was tested for all polymorphisms. Differences in CXCL5 plasma level between patients and control subjects were examined by the Mann-Whitney $U$ test and differences of CXCL5 protein expression between tumour and normal paired tissues were examined by the Wilcoxon's signed rank test. Correlations were analysed with Pearson's coefficient analyses. Statistical analysis was performed using the SPSS for Windows computer package (Rel. 11.5, 2002, Chicago: SPSS Inc.). Results were considered significant at a level of $\mathrm{P}<0.05$.

\section{Results}

CXCL5 polymorphism. To analyse the influence of CXCL5 on colorectal carcinogenesis we investigated the prevalence of promoter $-156 \mathrm{G} \rightarrow \mathrm{C}$ and exon $2+398 \mathrm{G} \rightarrow \mathrm{A}$ gene polymorphisms in $228 \mathrm{CRC}$ patients and 231 control subjects by a TaqMan system.

There was no significant difference in genotype distribution between CRC patients and control subjects or in allelic frequencies (Table I). Variant alleles at both loci were highly linked in CRC patients and control subjects. All individuals that were genotyped as $\mathrm{G} / \mathrm{G}$ for the promoter $-156 \mathrm{G} \rightarrow \mathrm{C}$ were also $\mathrm{G} / \mathrm{G}$ at the exon $2+398 \mathrm{G} \rightarrow \mathrm{A}$. Furthermore, all individuals that were $\mathrm{C} / \mathrm{C}$ for the promoter $-156 \mathrm{G} \rightarrow \mathrm{C}$ were also $\mathrm{A} / \mathrm{A}$ at the exon $2+398 \mathrm{G} \rightarrow \mathrm{A}$. The genotype and allelic distributions in CRC patients and control group were not associated with clinical characteristics such as age, gender, location or Dukes' stage. All genotype distributions were in Hardy-Weinberg equilibrium.

Plasma levels of CXCL5. To search for tumour markers, the plasma levels of CXCL5 were measured by ELISA in 62

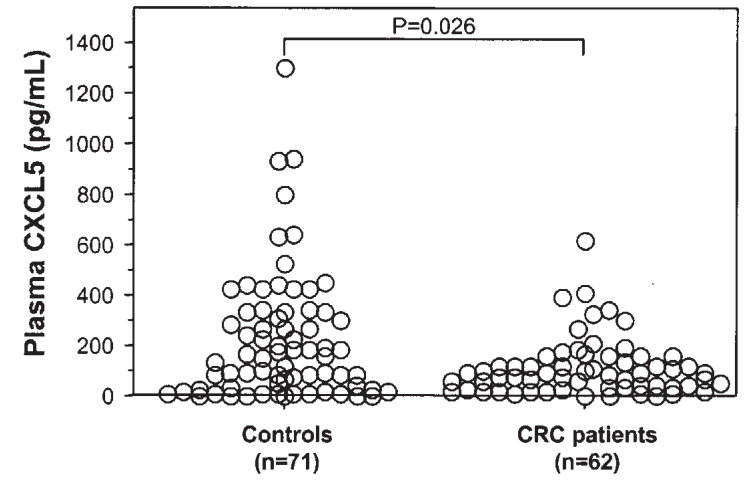

Figure 1. Plasma CXCL5 concentrations in healthy controls and colorectal cancer (CRC) patients. CRC patients have significantly lower concentrations compared with controls.

CRC patients and 71 healthy control subjects. The CXCL5 plasma concentration was lower in CRC patients [median 85 (range 0-614) pg/ml] than in controls [median 162 (range 0 -1299) $\mathrm{pg} / \mathrm{ml}$, with a statistical difference between these groups ( $\mathrm{P}=0.026)$ (Fig. 1). However, there were no differences between CXCL5 SNP variants and plasma levels in the CRC patients and in the control group (data not shown).

Levels of CXCL5 in colorectal tissue. CXCL5 protein concentration was measured by ELISA in protein-lysates of colorectal cancerous tissues and matched normal tissues from 80 patients. The levels of CXCL5 protein in cancer tissue [median 120 (range 0-3580) $\mathrm{pg} / \mathrm{mg}$ ] showed significant difference in comparison with normal tissue [median 10 (range 0-519) $\mathrm{pg} / \mathrm{mg}$ ] $(\mathrm{P}<0.0001)$, (Fig. 2). Evaluation of the relative expression (tumour vs. normal tissue) showed 96\% (77/80) up-regulation. When assessing this difference in detail we 


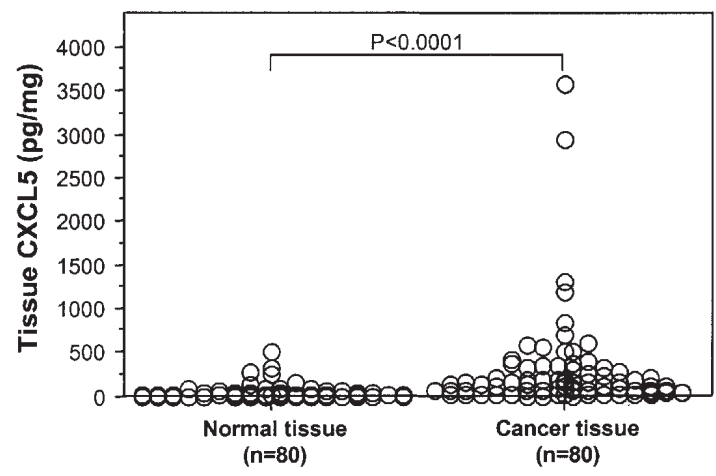

Figure 2. Relationship between CXCL5 protein levels in human CRC tissue and paired normal tissue. The CXCL5 protein level in cancer tissue was significantly higher compared with normal tissue.
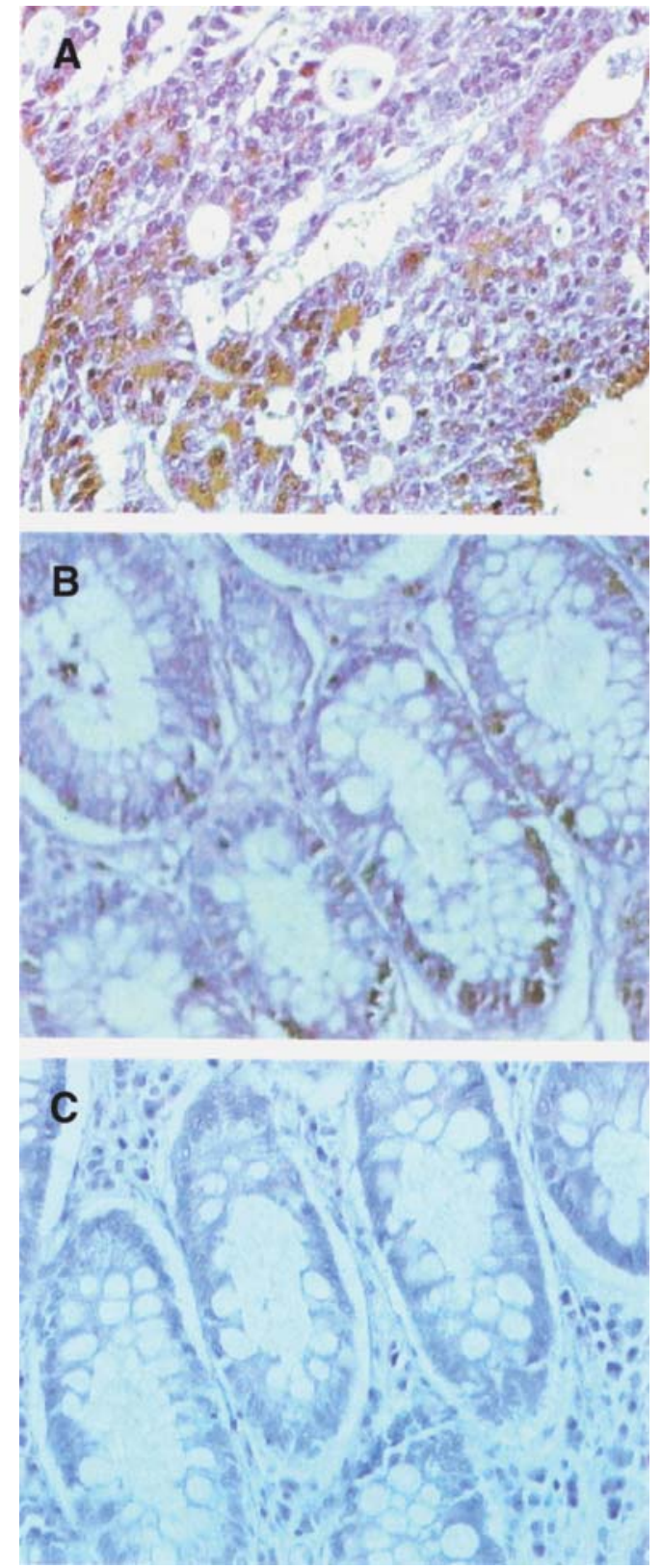

Figure 3. Images of immunohistochemical staining of CXCL5 in cancer and normal tissue from patients with colorectal cancer. CXCL5 protein expression is present in cancer (A) and in normal (B) epithelial cells. Control staining of normal tissue (C) with only the secondary antibody, demonstrating the specificity of the primary antibody.

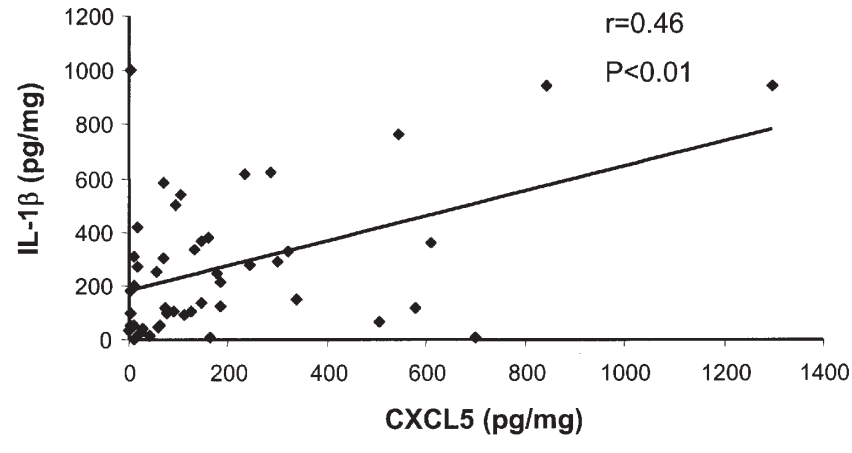

Figure 4. Correlation between IL-1ß and CXCL5 concentrations in the cancer tissue from CRC patients $(n=48)$.

found that patients who were $-156 \mathrm{C}$ carriers had significantly higher CXCL5 protein concentration [median 21 (range 0-131) $\mathrm{pg} / \mathrm{mg}$ ] compared with $-156 \mathrm{G} / \mathrm{G}$ carriers [median 9 (range 0$519) \mathrm{pg} / \mathrm{mg}](\mathrm{P}=0.027)$ in normal tissue. The CXCL5 protein level in cancerous tissue tended to be higher for patient $\mathrm{C}$ carriers [median 190 (range 5-3850) pg/mg] compared with $\mathrm{G} / \mathrm{G}$ carriers [median 99 (range 0-2942) pg/mg] $(\mathrm{P}=0.059)$.

The levels of CXCL5 protein in all the analyzed tissue and plasma samples from the CRC patients did not correlate with clinical characteristics such as age, gender, location and Dukes' stage (data not shown)

Immunohistochemical findings. Immunohistochemistry was performed in order to detect the site of CXCL5 protein expression. Immunohistochemical staining of CXCL5 protein showed that CXCL5 immunoreactivity was mainly evident in epithelial cells of the colorectal carcinoma and in epithelial cells in the resection border that reflects normal tissue (Fig. 3). The observations showed staining of CXCL5 protein in cancerous as well as non-cancerous tissue with an intensity of staining varying from none to strong.

Levels of IL-1 1 in colorectal tissue. Since IL- $1 \beta$ is suggested to regulate CXCL5 expression in colonic epithelial cells, the IL- $1 \beta$ protein concentration was determined by ELISA in protein-lysates of an available subset of colorectal cancerous tissues and matched normal tissues from 48 patients. The levels of IL-1ß protein in cancer tissue [median 190 (range $0-1003) \mathrm{pg} / \mathrm{mg}$ ] showed significant difference in comparison with normal tissue [median 13 (range 0-1190) pg/mg] $(\mathrm{P}<0.0001)$. Evaluation of the relative expression (tumour vs. normal tissue) showed $96 \%$ (46/48) up-regulation. Furthermore, the protein level of CXCL5 and IL-1ß in cancer tissue, of the subset investigated, were significantly correlated (Fig. 4) $(r=0.46, \mathrm{P}<0.01)$.

\section{Discussion}

In the present study we attempted to identify whether an association exists between the CXCL5 gene SNP variants $-156 \mathrm{G} \rightarrow \mathrm{C}$ and $+398 \mathrm{G} \rightarrow \mathrm{A}$ and $\mathrm{CRC}$. Our data showed that the genotype distribution and allelic frequencies were not significantly associated with CRC compared with controls. However, our findings confirm that the gene variant $-156 \mathrm{G} \rightarrow \mathrm{C}$ 
is highly linked with the gene variant $+398 \mathrm{G} \rightarrow \mathrm{A}(16-18)$. Moreover, we have for the first time been able to demonstrate the distribution of the two SNP variants in a Swedish population.

We also found a significantly higher CXCL5 protein expression in 77 of $80 \mathrm{CRC}$ tissues in comparison with matched normal tissue $(\mathrm{P}<0.0001)$, a result that confirms the finding in a study by Baier and colleagues, including a limited number of patients $(n=10)$ restricted to colon (19). Despite our larger sample collection, including information on clinical characteristics, we could not find an association to any of these, i.e. age, gender, location or Dukes' stage. IL-1ß is over-expressed in CRC related to normal tissue (8). In studies of CXCL5 regulation using human colon epithelial cells, proinflammatory stimuli such as IL-1ß has been shown to up-regulate CXCL5 (6). Therefore, we investigated the IL-1ß expression in a subset of our entire sample collection and the results showed that IL-1ß and CXCL5 expression correlated significantly. These findings may partly explain the elevated levels of CXCL5 found in CRC. Moreover, to identify the cellular source and localization of CXCL5 protein we used immunohistochemistry and found immunoreactivity mainly in cancer and normal epithelial cells.

Recently it has been reported that carriers of the $-156 \mathrm{C}$ variant allele have higher systemically circulating CXCL5 levels compared with wild-type homozygotes (18). They also noted that a higher prevalence of this allele was associated with increased leukocyte-produced CXCL5. However, the plasma and leukocyte-produced CXCL5 were not significantly correlated in the same sample from the study population.

In our study, using standard ELISA method, we noted that the range of the plasma CXCL5 concentration was comparable to other control groups $(18,20)$ and that the levels of plasma CXCL5 in CRC patients were significantly lower than in controls. However, we failed to detect any association between genotype and plasma concentration of CXCL5 in CRC patients or controls. The circulating and tissue concentrations of CXCL5 in CRC patients were not correlated with one another which can reflect that CXCL5 derives from different sources such as leukocytes, epithelial and endothelial cells. The reduced plasma concentration of CXCL5 in CRC patients relative to controls may indicate that $\mathrm{CRC}$ patients have an immunologic imbalance resulting in impaired production of CXCL5 from leukocyte and endothelial cells and/or restricts the secretion of CXCL5 from epithelial cells in colon and rectum.

When assessing a potential relation between genotype $(-156 \mathrm{G} \rightarrow \mathrm{C})$ and tissue concentration of CXCL5 we found that patients who were $\mathrm{C}$ carriers had significantly higher CXCL5 levels compared with G/G carriers in normal tissue and noted a trend showing higher CXCL5 concentration in cancerous tissue within the patient $\mathrm{C}$ carriers group. Whether $-156 \mathrm{C}$ allele is directly responsible for the elevated production of CXCL5 in CRC tissue or whether there is a linkage disequilibrium between this allele and other polymorphisms nearby remains to be elucidated. Overall, extended research including functional studies and larger study samples is required to reveal any influence of the $\mathrm{C}$ allele on the CXCL5 concentration in tissue as well as plasma in CRC patients.
The role of chemokines in tumour biology is complex. They have been suggested to regulate trafficking of leukocytes and may have impact on inflammation and carcinogenesis $(4,5)$. The CXCL5 regulates neutrophils homing to the intestinal mucosa and seems to contribute to the anti-tumour immunity (1-5). On the other hand CXCL5 has been suggested to play a partial role in regulating angiogenesis relevant to cancer (12) and thereby has a tumour growth function. For instance, CXCL5 has been associated with human non-small cell lung cancer and pancreatic cancer angiogenesis and thus contribute to tumourigenesis $(13,21)$.

The functional consequence of CXCL5 expression in human CRC is not yet established. Other chemokines, such as IL- 8 and GRO $\alpha$, with overlapping functions could have a complementary driving force for the development of CRC.

Little is known about the influence of CXCL5 gene polymorphisms on the levels of CXCL5 protein in human tissues. To our knowledge this is the first report on the influence of CXCL5 gene variants and their relation to expression of CXCL5 protein in human CRC. From a molecular point of view, the pathological significance of the observed findings remains open as long as the underlying mechanisms are unclear. The results presented in this study comprise the initial stage of forthcoming studies in our laboratory on intervention of chemokines regarding tumour growth, metastasis and clinical relevance in CRC.

\section{Acknowledgements}

This work was supported by grants from Futurum - the academy of healthcare, County Council of Jönköping, Sweden and the University College of Health Sciences, Jönköping, Sweden. We thank Marita Skarstedt (Ryhov County Hospital, Jönköping, Sweden) for excellent technical support.

\section{References}

1. Balkwill $\mathrm{F}$ and Mantovani A: Inflammation and cancer: back to Virchow? Lancet 357: 539-545, 2001.

2. Coussens LM and Werb Z: Inflammation and cancer. Nature 420: 860-867, 2002

3. Balkwill F: Chemokine biology in cancer. Semin Immunol 15: 49-55, 2003.

4. Dwinell MB, Johanesen PA and Smith JM: Immunobiology of epithelial chemokines in the intestinal mucosa. Surgery 133: 601-607, 2003.

5. Luster AD: Chemokine regulate lymphocyte homing to the intestinal mucosa. Gastroenterology 120: 291-294, 2001.

6. Keates S, Keates AC, Mizoguchi E, Bhan A and Kelly CP: Enterocytes are the primary source of the chemokine ENA-78 in normal colon and ulcerative colitis. Am J Physiol 273: G75-G82, 1997.

7. Walz A, Schmutz P, Mueller C and Schnyder-Candrian S: Regulation and function of the CXC chemokine ENA-78 in monocytes and its role in disease. J Leukoc Biol 62: 604-611, 1997

8. Miki C, Tonouchi H, Wakuda R, Hatada T, Inoue Y, Minato E, Kobayashi $\mathbf{M}$ and Kusunoki M: Intra-tumoral interleukin-6 downregulation system and genetic mutations of tumor suppressor genes in colorectal cancer. Cancer 94: 1584-1592, 2002.

9. Walz A, Burgener R, Car B, Baggiolini M, Kunkel SL and Strieter RM: Structure and neutrophil-activating properties of a novel inflammatory peptide (ENA-78) with homology of interleukin 8. J Exp Med 174: 1355-1362, 1991. 
10. Wen Y, Giardina SF, Hamming D, Greenman J, Zachariah E, Bacolod MD, Liu H, Shia J, Amenta PS, Barany F, Paty P, Gerald W and Notterman D: GRO(alpha) is highly expressed in adenocarcinoma of the colon and down-regulates fibulin-1. Clin Cancer Res 12: 5951-5959, 2006.

11. Strieter RM, Burdick MD, Gomperts BN, Belperio JA and Keane MP: CXC chemokines in angiogenesis. Cytokine Growth Factor Rev 16: 593-609, 2005.

12. Strieter RM, Burdick MD, Mestas J, Gomperts BN, Keane MP and Belperio JA: Cancer CXC chemokine networks and tumour angiogenesis. Eur J Cancer 42: 768-778, 2006.

13. Arenberg DA, Keane MP, DiGiovine B, Kunkel SL, Morris SB, Xue Y-Y, Burdick MD, Glass MC, Iannettoni MD and Strieter RM: Epithelial-neutrophil activating peptide (ENA-78) is an important angiogenic factor in non-small cell lung cancer. J Clin Invest 102: 465-472, 1998.

14. Rieder G, Einsiedl W, Hatz RA, Stolte M, Enders GA and Walz A: Comparison of CXC chemokines ENA-78 and interleukin-8 expression in Helicobacter pylori-associated gastritis. Infect Immun 69: 81-88, 2001.

15. Z'Graggen K, Walz A, Mazzucchelli L, Strieter RM and Mueller C: The C-X-C chemokine ENA-78 is preferentially expressed in intestinal epithelium in inflammatory bowel disease. Gastroenterology 113: 808-816, 1997.
16. Amoli MM, Larijani B, Thomson W, Ollier WE and Gonzalez-Gay MA: Two polymorphisms in the epithelial cell-derived neutrophil-activating peptide (ENA-78) gene. Dis Markers 21: 75-77, 2005.

17. Zineh I, Welder GJ and Langaee TY: Development and crossvalidation of sequencing-based assays for genotyping common polymorphisms of the CXCL5 gene. Clin Chim Acta 370: 72-75, 2006.

18. Zineh I, Aquilante CL, Langaee TY, Beitelshees AL, Arant CB, Wessel TR and Schofield RS: CXCL5 gene polymorphisms are related to systemic concentrations and leukocyte production of epithelial neutrophil-activating peptide (ENA-78). Cytokine 33: 258-263, 2006

19. Baier PK, Eggstein S, Wolff-Vorbeck G, Baumgartner U and Hopt UT: Chemokines in human colorectal carcinoma. Anticancer Res 25: 3581-3584, 2005.

20. Shokuhi S, Bhatia M, Christmas S, Sutton R, Neoptolemos JP and Slavin J: Levels of the chemokines growth-related oncogene $\alpha$ and epithelial neutrophil-activating protein 78 are raised in patients with severe acute pancreatitis. Br J Surg 89: 566-572, 2002.

21. Wente MN, Keane MP, Burdick MD, Friess H, Buchler MW, Ceyhan GO, Reber HA, Strieter RM and Hines OJ: Blockade of the chemokine receptor CXCR2 inhibits pancreatic cancer cellinduced angiogenesis. Cancer Lett 241: 221-227, 2006. 